\title{
Modeling Agile Organization Under Scrum Approach and Coordination
}

\author{
Naima Benkhider ${ }^{1}$, Sonia Kherbachi ${ }^{2,3}$ \\ ${ }^{1}$ LRMTQ, Department of Management, FSECSG, University of Bejaia, Algeria \\ ${ }^{2}$ Department of Management, FSECSG, University of Bejaia, 06000, Bejaia, Algeria \\ ${ }^{3}$ University of Science and Technology Beijing China, Beijing 100083, China
}

\begin{abstract}
Agile organization are raising much attentions to enhance efficient coordination by Scrum approach. The key takeaways for a study on Huawei product development (PD) project are: (i) Agile organization emphasize minimum valuable product (MVP) to rise efficient coordination; (ii) Preliminary information are paramount to the overlapping process between project teams supported by daily scrum; (iii) iteration risks are reduced under agile environment with windows of overlap. We discuss organizational improvement opportunities of our modeled DSM with possibilities for follow-on research.
\end{abstract}

Keywords: Agile organization, scrum approach, coordination, DSM

\section{Introduction}

Virtual teams' coordination is a current issue in project management since most of teams are geographically and temporally dispersed (Chamakiotis et al, 2020). It is crucial to ensure coordination between teams in order to guarantee the success of the development of complex product development (PD) projects by digital technologies. Setting up a technological infrastructure for virtual team requires an adjustment between the used technology and tasks performed (i.e. task-technology fit (TTF)). The virtual coordination elements are descriptive in nature such as team composition, task complexity, and technology functionality, and it is the relationships among them that define how team members coordinate with each other to perform the tasks and how PD project is carried out (Zhang et al, 2018). Moreover, virtual teams' coordination is the hard core of an agile approach when designing complex PD project. Scrum has been largely accepted as one of the most important agile approaches because during the planning iteration, daily inspection allows team members to meet to verify each other's' tasks and make appropriate revisions and adaptation. During the planning iteration, a list of requirements results (Mahnic \& Drnovscek, 2005 ). These requirements form the basis of learning curves (LC) (Egelman et al, 2016).

In this paper, we address the design structure matrix (DSM) method to illustrate coordination strength among a single-team members and the overlapping process between virtual teams upon scrum approach. We present a relevant literature review regarding coordination between virtual teams in agile environment. An agile organization from Huawei P30 PRO project is used to validate our concepts and method 


\section{Related work}

Mapping of agile tasks' coordination into a DSM model is an emergent research issue in PD projects (Bajpai et al, 2019). Most of scholars and practitioners used process DSM optimization. The early process DSM optimization goal was to "push" the feedback markers in the DSM matrix to the lower left corner of the matrix (diagonal), or block diagonalize ( block diagonalization) (Eppinger \& Browning, Design Structure Matrix Methods and Applications, 2012) to reduce iteration and rework. There are two ways to achieve this: 1) reduce the amount of feedback in DSM (Steward, 1981), (Danilovica \& R.Browning, 2007), (Kherbachi \& Yang, 2016); 2) minimize the length of feedback (Fu \& Chen, 2012); (Sarica \& Luo, 2019). In general, teams share a common interest in getting the PD project done in a minimum duration (Mazzara \& Sillitti, 2018). Such organization have progressed from a waterfall approach to one more agile (Bajpai et al, 2019). Agile tasks' coordination under virtual organization improves the overall agile project management when the technology used is adjusted to the tasks performed through TTF. Agile tasks' coordination consist to define the assignments to be carried out by each virtual team across an overlap window to keep up teams and tasks' synchronization by strengthening the communication tie (Yang, et al, 2015).

The need to improve performance and productivity in development complex PD projects has resulted in the application of digital technologies and approaches such as mobile computing and internet of people (Howard et al, 2019) which are the basis of coordination tools. This development has altered the product and process design, process flows, organizational structure, and other relevant aspects of how products are made.

In addition to the digital technology used, learning curves are an important tool for strengthening coordination between teams (Ramirez et al, 2020). An important aspect of this previous work on LC is that it focuses on the process rather than on the product to make modification if necessary or to predict future needs (Egelman et al , 2016).

\section{Agile coordination among virtual teams}

Figure 1 capture the coordination among virtual teams. The DSM of agile PD presents the process used by a single-team to design complex PD in an agile organization (illustrated in Figure 1 (a)). In this process, the team members work on coupled with feedback communication through the sprint planning, the daily scrum and at the end, with a sprint review to perform a retrospective (Naik, Jenkins, \& Newell, 2020) in order to reduce the amount of rework (Yang et al, 2019). The daily scrum serves to coordinate team's tasks with different information flow. This DSM can be developed in many ways. For instance, it may present a sprint in cross-functional team, and the sum of these sprint represent the overall agile process.

Team $i$ coordinate its tasks in order to produce reliable information. These information serves as primarily information to team $j$ as shown in Figure 1 (b) in order to reduce the amount of rework; the feed forward overlapping in team 2 because of primarily information from team 1 reducing the rework time in activity B performed by team 2 . Virtual teams work on overlap to ensure the communication tie and coordination strength. In the overlapping process, the schedule is accelerated by starting a downstream process before 
finishing an upstream one using different information flow; which is the case of teams 3 and 4 involved in activity $\mathrm{C}$ with activity $\mathrm{B}$ performed by team 2 . The overlapping process is used to curtail the design stage and also to recast the downstream design activities. PD design can receive a design parameter in three states: preliminary design parameters by estimation using preliminary information, from a complete analysis through finalized information, and confirmed after verification of the redesign.

Figure 1. Coordination among virtual teams

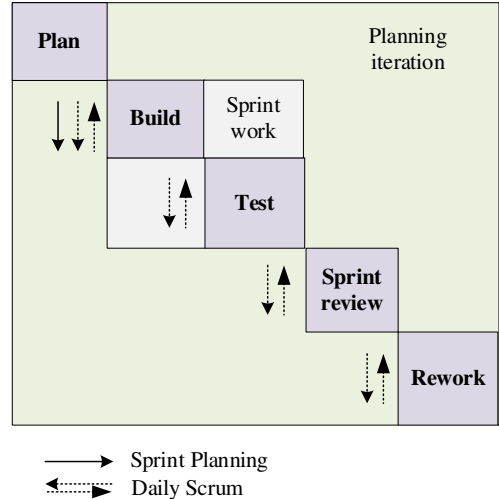

(a) DSM of agile product development for a single team

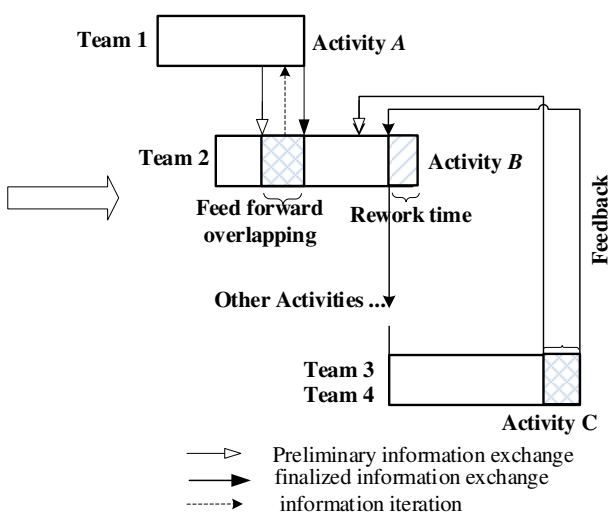

(b) Overlapping process

Source: illustrated by authors in reference to (Bajpai, Eppinger, \& Joglckar, 2019)

Supporting agile team coordination, digital technologies enables teamwork within as well as across organizational boundaries. In this paper, we assume that coordination between virtual teams in PD organization first require coordination between members of a singleteam in order to make the necessary information to other teams to accomplish the PD process in an agile approach to decrease the rework risk as provided by the findings of (E.D.Love \& Irani, 2019) (see Figure 1). Additionally, learning curves LC enables to identify what revisions are required in PD process designing which enable the decrease of rework risk at a later stage of PD process building. In this study, LC is appreciated as a result of daily scrum in the sprint iteration (see Figure 1 (a)) when team members design PD project. It also, may approached as an output of overlapping process between virtual teams (see Figure 2 (b)). The LC is illustrated in equation 1 (Globerson \& Millen, 1989)

$$
C L(i)=x \cdot W_{-} \text {need }_{\mathrm{o}}{ }^{n}
$$

where $L C$ is expressed as the working hours needed to perform the $\mathrm{X}^{\text {th }}$ repetition; $x$ is the number of repetitions performed after daily scrum or overlapping process; $W_{-}$need $_{0}$ is the working hours needed the first time this task was performed; and $\boldsymbol{n}$ is the learning intensity. To minimize the number of iterations (feedbacks) in DSM, (Steward, 1981) proposed the following objective function:

$$
f=\sum_{i=1}^{n} \sum_{j=i+1}^{n} w(i, j)
$$


Among them, $w(i, j)$ is the binary value in DSM. Aiming at the goal of minimizing the feedback length expressed as the iteration risk, the objective function proposed by (Kherbachi, 2019) and followed by (Sarica \& Luo, 2019) is :

$$
f=1-\prod_{z=1}^{3}\left(1-w^{(z)}(i, j)\right)
$$

where $z$ is the number of paths propagation. For a simple DSM, because it contains fewer elements, it can be optimized by using the above method, that is, based on the decoupling process to optimize the ranking algorithm, the order and coupling of activities can be easily determined, thereby reducing the amount of information feedback above the diagonal or minimize the length of the feedback. We propose that the maximum reduction in project time is the optimization goal in the case of overlap function regarding the impact length propagation (Yang et al., 2016) in equation (4) :

$$
\mathrm{MVP}=\left\{\begin{array}{l}
\max \Delta T=\sum_{i=1}^{n}\left(T_{o v}(i)-\left(\Delta T_{1}(i)+\Delta T_{2}(i)\right)\right)-T_{I R} \times C L \\
\min f=1-\prod \sum_{z=1}^{3}\left(1-w^{(z)}(i, j)\right)
\end{array}\right.
$$

Among them, Tov (i) is the total overlap time of activity i, $\Delta$ T1 (i) is the total amount of sequence overlap caused by receiving information from upstream activities, and $\Delta \mathrm{T} 2$ (i) is the total amount of feedback overlap caused by receiving feedback information from downstream activities. Their sum represents the total feedback in the project. $\mathrm{T}_{\mathrm{IR}}$ is the indirect rework time caused by feedback for the entire project; the difference of time between the estimated duration of the project and potential duration under agile environment. $m$ represents the number of $j$ 's teams involved with team $i$. In fact, it is focused on LC and on the use of the agile approach to obtain the minimum valuable product (MVP) function. MVP reveals efficient situation for shortening the project duration by maximizing the window overlap related potential propagation of iteration risks.

\section{Case study}

We use Huawei P30 pro project to verify the proposed concepts and model. P30 pro project involves a large number of activities and teams. Since we focus on the impact of LC and iteration risk on coordination between single-team members and among teams. We selected the 23 teams involved with the 46 activities and their involvement degree. Huawei P30 PRO project teams $[\mathrm{B}, \mathrm{C}, \mathrm{D}, \mathrm{G}, \mathrm{I}, \mathrm{J}, \mathrm{N}, \mathrm{O}]$; [F, G, I, P] ; [F, G, I, K] ; [A, C, D, G] ; [B, C, $\mathrm{S}]$; [A, B, E, H, U] ; [E, M, N, Q] ; [A, C, H, I, N, P, Q, S, T ; [D, G, M, P] ; [S] ; [A, N, $\mathrm{W}] ;[\mathrm{T}, \mathrm{V}] ;[\mathrm{V}, \mathrm{W}] ;[\mathrm{U}, \mathrm{W}]$ perform activities from 1 to 14 respectively (see Table 1 ). A single-team is composed of 8 members. In this project, teams use TTF as coordination tools, in particular mobile computing and Internet of people. 
Benkhider, Naima; Kherbachi, Sonia

Table 1. Tasks related activities and their duration

\begin{tabular}{|c|c|c|c|c|}
\hline Activities & Teams & Tasks & Task Duration & Activities Duration \\
\hline \multirow{4}{*}{ Acivity 1} & \multirow{4}{*}{$\mathrm{B}, \mathrm{C}, \mathrm{D}, \mathrm{G}, \mathrm{I}, \mathrm{J}, \mathrm{N}, \mathrm{O}$} & 1 & 20 & \multirow{4}{*}{56} \\
\hline & & 7 & 10 & \\
\hline & & 9 & 11 & \\
\hline & & 13 & 15 & \\
\hline \multirow{4}{*}{ Activity 2} & \multirow{4}{*}{$F, G, I, P$} & 17 & 32 & \multirow{4}{*}{73} \\
\hline & & 20 & 11 & \\
\hline & & 21 & 12 & \\
\hline & & 23 & 18 & \\
\hline \multirow{2}{*}{ Activity 3} & \multirow{2}{*}{$F, G, I, K$} & 31 & 10 & \multirow{2}{*}{14} \\
\hline & & 32 & 4 & \\
\hline \multirow{3}{*}{ Activity 4} & \multirow{3}{*}{$\mathrm{A}, \mathrm{C}, \mathrm{D}, \mathrm{G}$} & 2 & 12 & \multirow{3}{*}{30} \\
\hline & & 4 & 8 & \\
\hline & & 6 & 10 & \\
\hline \multirow{3}{*}{ Activity 5} & \multirow{3}{*}{$\mathrm{B}, \mathrm{C}, \mathrm{S}$} & 11 & 10 & \multirow{3}{*}{74} \\
\hline & & 12 & 4 & \\
\hline & & 16 & 60 & \\
\hline \multirow{3}{*}{ Activity 6} & \multirow{3}{*}{$\mathrm{A}, \mathrm{B}, \mathrm{E}, \mathrm{H}, \mathrm{U}$} & 24 & 18 & \multirow{3}{*}{31} \\
\hline & & 30 & 8 & \\
\hline & & 44 & 5 & \\
\hline \multirow{4}{*}{ Activity 7} & \multirow{4}{*}{$\mathrm{E}, \mathrm{M}, \mathrm{N}, \mathrm{Q}$} & 3 & 15 & \multirow{4}{*}{44} \\
\hline & & 5 & 9 & \\
\hline & & 8 & 12 & \\
\hline & & 10 & 8 & \\
\hline \multirow{6}{*}{ Activity 8} & \multirow{6}{*}{$\mathrm{A}, \mathrm{C}, \mathrm{H}, \mathrm{I}, \mathrm{N}, \mathrm{P}, \mathrm{Q}, \mathrm{S}, \mathrm{T}$} & 18 & 10 & \multirow{6}{*}{48} \\
\hline & & 19 & 10 & \\
\hline & & 22 & 10 & \\
\hline & & 25 & 10 & \\
\hline & & 33 & 4 & \\
\hline & & 34 & 4 & \\
\hline & & 37 & 30 & \\
\hline & & 38 & 15 & \\
\hline Activity 9 & $\mathrm{D}, \mathrm{G}, \mathrm{M}, \mathrm{P}$ & 39 & 10 & 15 \\
\hline & & 40 & 20 & \\
\hline & $\mathrm{S}$ & 45 & 4 & 14 \\
\hline Activity 10 & $\mathrm{~S}$ & 46 & 10 & 14 \\
\hline Activity 11 & $\mathrm{~A}, \mathrm{~N}, \mathrm{~W}$ & 14 & 54 & 74 \\
\hline & $A, N, W$ & 15 & 20 & 14 \\
\hline & & 26 & 6 & \\
\hline Activity 12 & $T, V$ & 27 & 17 & 51 \\
\hline & & $\frac{28}{29}$ & $\frac{20}{8}$ & ה \\
\hline & & 35 & $\frac{0}{10}$ & \\
\hline Activity 13 & $V, W$ & 36 & 4 & 14 \\
\hline & & 41 & 14 & \\
\hline Activity 14 & $\mathrm{U}, \mathrm{W}$ & 42 & 8 & 34 \\
\hline & & 43 & 12 & \\
\hline
\end{tabular}

Source: performed by authors using Huawei's data

In Huawei P30 PRO project, each team holds two daily scrums, which give $\mathrm{x}=2$ in equation 1 (i.e. in the beginning of the day before starting the activity and daily off-work). The ultimate purpose of these meeting is to synchronize the work of all team members in order to decrease the amount of feedback in return, to reduce the amount of rework by answering three questions: What have you done on this project since the last Daily Scrum Meeting? What will you do before the next meeting? Do you have any obstacles? Daily scrum is an important support to the team LC where they share their experience and knowledge. In this paper, LC for each team is based on team's common expertise $(n)$ as given in equation 1 . $n$ is estimated at $80 \%$ for the teams $[\mathrm{K}, \mathrm{S}, \mathrm{I}, \mathrm{Q}, \mathrm{C}, \mathrm{L}, \mathrm{T}, \mathrm{A}, \mathrm{J}, \mathrm{W}]$ and at $65 \%$ for the rest of the teams according to project manager and leaders of teams. Common expertise emphasizes the shared experience between team's member working on sprint (see Figure 1 (a)). In this regard, the higher the common expertise, the higher the LC is increasing. Thus, conflicts between team's member are reduced and the PD process is accelerating. As 
a result, the higher the LC, the lower rework time is decreasing, therefore the rework risk is minimized.

As indicate above, the output of daily scrum serves as an input to other teams. It is used as preliminary information to reduce the rework time (see Figure 1). To reflect feedback iteration in PD project teams, we used the total feedback which is appreciated through the sum of the total amount of sequence overlapping caused by receiving information from upstream and downstream activities, as shown in equation 4. Optimizing coordination between virtual PD organization is sustained by the maximum of overlap window. Virtual task's coordination serves to reduce the amount of feedback between teams or to minimize the iteration risk. The overlap window allows teams to work on an agile approach and maximize their LC. As a result, the amount of rework is reduced, so that the duration of PD project decreases, consequently the MVP is achieved (see equation 4).

As illustrated in Figure 2, each team is assigning part of its working hours to perform a specific task. This time is expressed in rate to represents the involvement degree of team $i$ in activity $j$. For example, 0.2 in DSM cell indicates that $20 \%$ of 8 hours of daily work is involved for the considered task, and so on. DSM shows also teams involving in activity 6 (as given in Table 1), For instance, team $H$ attribute $80 \%$ of its working hours for task 30 which rise the $\mathrm{LC}$ of this team $(\mathrm{LC}=1)$, therefore it reduces the rework time regarding activity $6\left(\mathrm{~T}_{\mathrm{IR}}=0.3\right)$. We can observe that team $B$ allocates only $20 \%$ of its working hours to perform the same task, this can be explained by a very low degree of involvement of this team, where its total feedback is about 5 iterations, and this is reflected in team's LC which is only equal to 0.4 , this come down to the absence of common expertise between team members $(n=65 \%)$.

Figure 2. Working daily hours spent on a task by each team

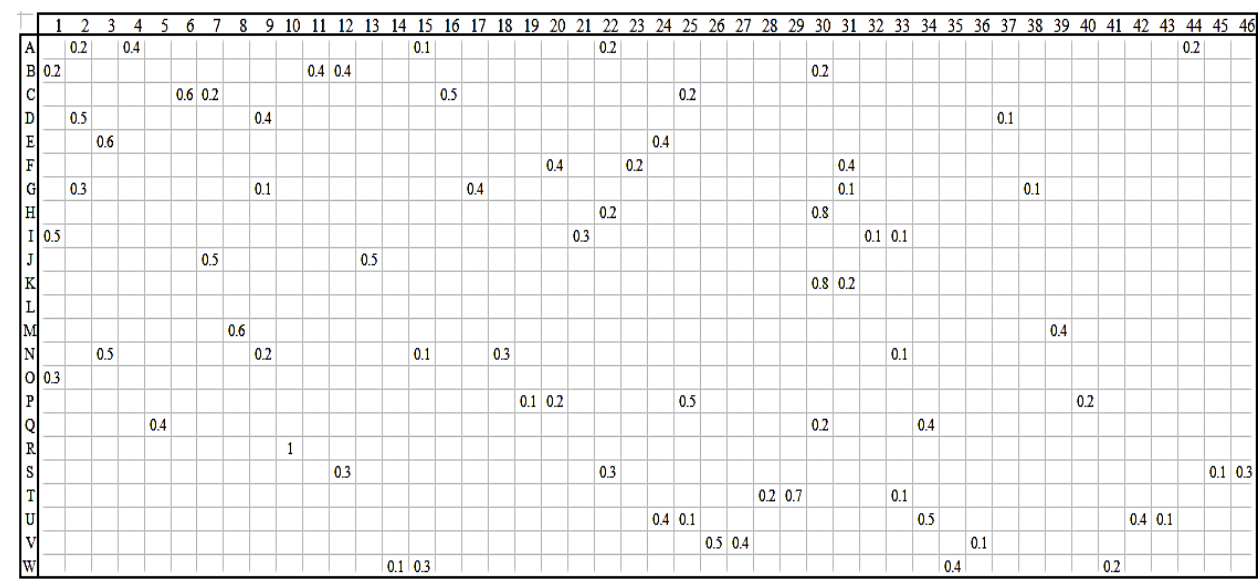

Source: illustrated by authors using Huawei's data

As mentioned above MVP reveal the efficient situation for reducing the project duration by maximizing the window overlap related potential propagation of iteration risks. According to Table 2, for team $B, \mathrm{MVP}=0,157$ which means its members optimize their 
coordination, in addition to maximizing the overlap window with other teams in order to shorten the overall project duration. For the team $H, \mathrm{MVP}=-0.058$. In this case, the negative value of MVP indicates that even with an overlap as such $\left(T_{O V}=0.019\right)$ it remains insufficient to remedy iterations which can be explained by a very large propagation risk $(w=0.953)$.

In this study, we first focused on a single-team members coordination through agile method which is scrum approach, then we draw attention to coordination strength between teams in virtual PD organization where TTF is the hard core of coordination tools. A single-team members adopt the sprint method to coordinate their tasks and minimize the amount of feedback. The output of this approach constitutes the input of agile task coordination between PD project teams by using it as an information flow in the overlapping process. The main purpose of this agile organization is to enhance the coordination between teams in order to decrease the amount of rework of the entire project, therefore to shorten the project duration. Moreover, the rework risk is decreased with teams' LC which is based on the shared knowledge and learning; that is, a common expertise can be a main source of project duration reduction, particularly in virtual PD organization where teams are geographically and temporally dispersed. Based on an agile organization and LC, teams can reach their MVP. In other words, they look for the efficient situation to decrease the overall project duration.

Table 2. Agile tasks' coordination under virtual PD organization

\begin{tabular}{|c|c|c|c|c|c|c|}
\hline Teams & CL & MIN propagation w & total feedback & Tov & Tir & MVP \\
\hline $\mathbf{A}$ & 0,88 & 0,953092114 & 9 & 0,017233115 & 0,3 & 0,110071232 \\
\hline B & 0,4 & 0,582569631 & 5 & 0,020220987 & 0,1 & 0,157170317 \\
\hline $\mathrm{C}$ & 0,75 & 0,732518123 & 7 & 0,016211229 & 0,6 & $-0,161863403$ \\
\hline D & 0,67 & 0,582602661 & 5 & 0,017618926 & 0,1 & 0,132772378 \\
\hline $\mathbf{E}$ & 1 & 0,434311832 & 4 & 0,018665125 & 0,2 & $-0,044752082$ \\
\hline $\mathbf{F}$ & 0,67 & 0,534045321 & 5 & 0,0058972 & 0,3 & 0,010494104 \\
\hline G & 0,4 & 1 & 10 & 0,016474518 & 0,8 & 0,098308091 \\
\hline $\mathbf{H}$ & 1 & 0,66073146 & 6 & 0,018955204 & 0,3 & $-0,058085639$ \\
\hline I & 0,5 & 0,41199928 & 4 & 0,01189124 & 0,1 & 0,112021803 \\
\hline $\mathbf{J}$ & 1 & 0,694033938 & 7 & 0,007638209 & 0,6 & $-0,303290383$ \\
\hline $\mathbf{K}$ & 1 & 0,420275428 & 4 & 0,017101928 & 0,2 & $-0,043188885$ \\
\hline $\mathbf{L}$ & 0 & 0,847493291 & 8 & 0 & 0 & 0,347826087 \\
\hline M & 1 & 0,453769737 & 4 & 0,000434783 & 0,6 & $-0,426521739$ \\
\hline $\mathbf{N}$ & 0,48 & 0,577438555 & 5 & 0,020415118 & 0,2 & 0,100976186 \\
\hline O & 0,6 & 0,885426375 & 8 & 0,010473576 & 0,1 & 0,277352511 \\
\hline $\mathbf{P}$ & 0,5 & 0,675812447 & 6 & 0,015637959 & 0,7 & $-0,104768393$ \\
\hline Q & 0,67 & 0,411272419 & 4 & 0,018290201 & 0,1 & 0,088622842 \\
\hline $\mathbf{R}$ & 1 & 0,770226619 & 7 & 0,001521739 & 0,4 & $-0,097173913$ \\
\hline $\mathbf{S}$ & 0,5 & 0,425921116 & 4 & 0,019530416 & 0,2 & 0,054382628 \\
\hline $\mathbf{T}$ & 0,67 & 0,673145644 & 6 & 0,005154905 & 0,5 & $-0,07928534$ \\
\hline $\mathbf{U}$ & 0,6 & 0,422222 & 2 & 0,026591307 & 0,4 & $-0,179634785$ \\
\hline $\mathbf{v}$ & 0,67 & 0,4100222 & 3 & 0 & 0,3 & $-0,070565217$ \\
\hline $\mathbf{W}$ & 0,5 & 0,3332144 & 4 & 0,007222272 & 0,1 & 0,116690772 \\
\hline
\end{tabular}




\section{Conclusion}

In compliance with the research orientation, this paper explores coordination paradigm in virtual PD organization under agile environment. We have zoom on the agile approach across teams' learning curve to reduce the rework by minimizing the amount of feedback and iteration risk and maximizing the window overlap between virtual teams. Minimum valuable product (MVP) among team is used to reflect the ability of team to interact with agility in each phase of a project. Results on Huawei P30 PRO project indicate that virtual teams are in a situation aiming for an efficient situation to decrease the overall project duration by coordinating their tasks under an agile environment.

Additional needed effort have to be done considering other latent variables which are unspoken to explore the main reasons of negative MVP values due to a high risk of iteration.

\section{References}

Bajpai, S., Eppinger, S. D., \& Joglckar, N. R. (2019). The Structure of Agile Development Under Scale Planning and Coordination. International Dependency and Structure Modeling Conference, 21, pp. 25-34. Monterey, CA, USA.

Chamakiotis, P., Boukis, A., \& Papadopoulos, N. P. (2020). The role of temporal coordination for the fuzzy front-end of innovation in virtual teams. International Journal of Information Management, 50, 182-190.

Danilovica, M., \& R.Browning, T. (2007). Managing complex product development projects with design structure matrices and domain mapping matrices. International Journal of Project Management, 25(3), 300-314.

E.D.Love, P., \& Irani, Z. (2019). Making sense of rework and its unintended consequence in projects: The emergence of uncomfortable knowledge. International Journal of Project Management, 37(3), 501-516.

Egelman, C. D., Epple, D., Argote, L., \& Fuchs, E. R. (2016). Learning by Doing in Multiproduct Manufacturing: Variety, Customizations, and Overlapping Product Generations. Management Science, 1-19.

Eppinger, S. D., \& Browning, T. R. (2012). Design Structure Matrix Methods and Applications. Cambridge: MA: MIT Press.

Fu, Y., \& Chen, F. (2012). Impact propagation and risk assessment of requirement changes for software development projects based on design structure matrix. International Journal of Project Management, 30(3), 363-373.

Globerson, S., \& Millen, R. (1989). Determining learning curves in group technology settings. International Journal of Production Research, 27(10), 1653-1664.

Hossain, M., \& Chua, D. (2014). Overlapping design and construction activities and an optimization approach to minimize rework. International Journal of Project Management, 56(6), 983-994.

Howard, M. C., Rose, J. C., Alabama, S., College, M., \& States, U. (2019). Information \& Management Refining and extending task - technology fit theory : Creation of two task - technology fit scales and empirical clarification of the construct. Information and Management, 56(6), 1-16.

Kherbachi, S. (2019). Managing risk of product development projects with similarity of propagation effects. Economic Researcher Review (CHEEC), 7(11), 128-146. 
Kherbachi, S., \& Yang, Q. (2016). Predicting technical communication in global product development projects related change propagation. Journal of Modern Project Management, 7(2), 85-89.

Mahnic, V., \& Drnovscek, S. (2005). Agile Software Project Management with Scrum. EUNIS Conference, (pp. 1-6).

Mazzara, M., \& Sillitti, A. (2018). The Agile Coordination Processes. Dans P. Ciancarini, S. Litvinov, A. Messina, A. Sillitti, G. Succi, \& Springer (Éd.), Proceedings of 5th International Conference in Software Engineering for Defence Applications: SEDA 2016 (pp. 41-51).

Naik, N., Jenkins, P., \& Newell, D. (2020). Learning Agile Scrum Methodology Using the Groupware Tool Trello Through Collaborative Working. Dans L. Barolli, F. Hussain, \& M. Ikeda (Éd.), Complex, Intelligent, and Software Intensive Systems. CISIS 2019. 993, pp. 343-355. Advances in Intelligent Systems and Computing, Springer, Cham.

Ramirez, R., Bhatti, Y., \& Tapinos, E. (2020). Exploring how experience and learning curves decrease the time invested in scenario planning interventions. Technological Forecasting and Social Change, 151, 1-15.

Sarica, S., \& Luo, J. (2019). An infinite Regression Model of Design change propagation in complex systems. IEEE systems Journal, 13(4), 3610-3618.

Steward, D. V. (1981). The design structure system: a method for managing the design of complex systems. IEEE Transactions on Engineering Management, 28(3), 71-74.

Yang, Q., Jiarui, L., \& Kherbachi, S. (2016). Progress in modeling and optimization for complex R\&D project based on design structure matrix. Systems Engineering: Theory and practice, 36(4), 989-1002.

Yang, Q., Kherbachi, S., Hong, Y., \& Shan, C. (2015). Identifying and managing coordination complexity in global product development project. International Journal of Project Management, 33(7), 1464-1475.

Yang, Q., Yang, N., Browning, T., Jiang, B., \& Yao, T. (2019). Clustering Product Development Project Organization from the Perspective of Social Network Analysis. IEEE transactions on Engineering Management, 61(1), 159-170.

Zhang, Y., Sun, J., Yang, Z., \& Wang, Y. (2018). Mobile social media in interorganizational projects: Aligning tool, task and team for virtual collaboration effectiveness. International Journal of Project Management, 36, 1096-1108.

Contact: Sonia KHERBACHI, Department of Management, FSECSG, University of Bejaia, 06000, Bejaia, Algeria, +213 7958347 92, soniakherbachi@ gmail.com 